\title{
Current human brain applications and challenges of dynamic hyperpolarized carbon-13 labeled pyruvate MR metabolic imaging
}

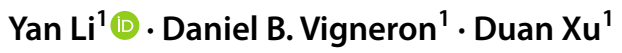

Received: 20 March 2021 / Accepted: 27 July 2021 / Published online: 25 August 2021

(c) The Author(s) 2021

\begin{abstract}
The ability of hyperpolarized carbon-13 MR metabolic imaging to acquire dynamic metabolic information in real time is crucial to gain mechanistic insights into metabolic pathways, which are complementary to anatomic and other functional imaging methods. This review presents the advantages of this emerging functional imaging technology, describes considerations in clinical translations, and summarizes current human brain applications. Despite rapid development in methodologies, significant technological and physiological related challenges continue to impede broader clinical translation.
\end{abstract}

Keywords Hyperpolarized $\cdot$ Metabolic imaging $\cdot$ Carbon-13 $\cdot$ Lactate $\cdot$ Pyruvate

\section{Introduction}

Metabolism is key to the comprehensive assessment of tissue conditions and functions. Alterations in metabolites often precede anatomic and microstructural changes. Improved characterization of metabolism will facilitate the understanding of disease mechanisms, enable early detection and intervention, as well as identify new avenues for the development of therapeutic strategies. Emerging personalized and precision medicine approaches have highlighted the need of advanced neuroimaging methods to detect metabolism noninvasively. However, measuring metabolism in vivo faces multiple challenges, including low metabolite concentrations, rapidly varying metabolic conditions, and slow signal detection rate. Over the years, numerous techniques have been used to interrogate the metabolic pathways and provided valuable insights into metabolic biomarkers. This review will concentrate on a novel real-time dissolution dynamic nuclear polarization (d-DNP) hyperpolarized (HP) carbon-13 $\left({ }^{13} \mathrm{C}\right)-$ labeled pyruvate MR metabolic imaging

This article is part of the Topical Collection on Technology

Yan Li

yan.li@ucsf.edu

1 Department of Radiology and Biomedical Imaging, UCSF Radiology, University of California, 185 Berry Street, Ste 350, Box 0946, San Francisco, CA 94107, USA with its advantages, considerations in clinical translation, current human brain data, and then its challenges.

\section{Advantages of dynamic hyperpolarized ${ }^{13} \mathrm{C}$ MR metabolic imaging}

Traditionally, MRI has offered the ability to detect steadystate metabolites in tissue using spectroscopic methods. Major metabolites that are routinely quantified in the in vivo brain using proton $\left({ }^{1} \mathrm{H}\right)$ MR spectroscopy (MRS) are choline, creatine, $\mathrm{N}$-acetyl aspartate (NAA), lactate (detectable under certain conditions), and other less concentrated or J-coupled metabolites such as glutamate and gamma-aminobutyric acid (GABA). These metabolites are crucial indicators of tissue function. For example, as a membrane-bound compound, high choline results from faster membrane turnover (more free, detectable choline), indicating either rapid brain maturation in newborns $[1,2]$ or degeneration such as in cases of brain tumors $[3,4]$; NAA is a neuronal marker, with low levels indicating loss of neurons or neuronal function; glutamate and GABA, the main excitatory and inhibitory neurotransmitters in the brain, have been correlated to the symptom severity in neurologic and psychiatric diseases [5-7]. While these metabolites can indicate brain disorders, they are generally nonspecific and must be used in conjunction with imaging or other clinical indicators for diagnostic purposes. The recent detection of 2-hydroxyglutarate (2HG) using ${ }^{1} \mathrm{H}$ MRS [8-10], a hallmark of isocitrate dehydrogenase (IDH) mutation in gliomas [11, 12], has opened new 
avenues of exploring cancer-specific metabolic pathways noninvasively. While it provides estimates of steady-state levels of metabolites associated with biological properties of the tumor, they are not able to assess rapid biologic changes within the tumor.

PET is another imaging modality that provides molecular and functional information using radioactive isotopes that have advanced the diagnosis and detection of pathologies. The most common radionuclides include fluoride-18 $\left({ }^{18} \mathrm{~F}\right)$ and carbon- $11\left({ }^{11} \mathrm{C}\right)$. The half-life or decay rate, $110 \mathrm{~min}$ and $20 \mathrm{~min}$ for ${ }^{18} \mathrm{~F}$ and ${ }^{11} \mathrm{C}$, determines when cyclotron radiopharmacy has to produce the imaging agents and the time for injecting the probes. The recent development of PET/MR scanners provide the opportunities to reduce the total time required to obtain both types of images and enable simultaneous correlation of high-resolution structural images with functional biochemical processes [13]. By far, ${ }^{18} \mathrm{~F}$-fludeoxyglucose $\left({ }^{18} \mathrm{~F}-\mathrm{FDG}\right)$, a glucose analog, is the most commonly used radioactive isotope for clinical applications. Due to the high background uptake of the normal brain parenchyma and limited specificity in distinguishing between progressive tumor and post-treatment inflammation [14], ${ }^{18}$ F-FDG PET is not routinely used for imaging brain tumors. However, ${ }^{18}$ F-FDG PET provides diagnostic information in the assessment for cognitive impairment and dementia $[15,16]$ and plays a critical role in guiding surgical resection for patients with epilepsy [17], with distinct hypometabolism seen in most non-lesional (MRI-negative) temporal lobe epilepsy $[18,19]$. While the discovery and implementation of new radiotracers provide value in evaluating various tumor and neurologic diseases, the uptake only reflects the accumulation of radioactive substances.

$\mathrm{HP}{ }^{13} \mathrm{C}$ MR metabolic imaging is a new molecular imaging modality that provides information about real-time metabolism [20-22]. Several reviews have described the method in detail [23, 24]. Fundamentally, this technique pre-polarizes ${ }^{13} \mathrm{C}$-enriched naturally occurring molecules (stable isotopes) using dissolution dynamic nuclear polarization (d-DNP) developed in 2003 [20] by transferring polarization of free radicals or electronic paramagnetic agent to ${ }^{13} \mathrm{C}$-labeled probes, delivers them intravenously, and measures the dynamic changes in ${ }^{13} \mathrm{C}$ signals using MRS or frequency selective imaging acquisitions. $\left[1-{ }^{13} \mathrm{C}\right]$ pyruvate, an endogenous metabolite, is the most widely studied $\mathrm{HP}{ }^{13} \mathrm{C}$ probe. It converts to $\left[1-{ }^{13} \mathrm{C}\right]$ lactate via lactate dehydrogenase $(\mathrm{LDH}),\left[1-{ }^{13} \mathrm{C}\right]$ alanine via alanine transaminase (ALT), and ${ }^{13} \mathrm{C}$ carbon dioxide $\left({ }^{13} \mathrm{CO}_{2}\right)$ via pyruvate dehydrogenase (PDH) within the mitochondria, which is then catalyzed to ${ }^{13} \mathrm{C}$-bicarbonate by carbonic anhydrase (CA) (Fig. 1) [25]. This highlights $\left[1-{ }^{13} \mathrm{C}\right]$ pyruvate's unique position to probe anaerobic glycolysis and mitochondrial oxidative metabolism. HP $\left[1-{ }^{13} \mathrm{C}\right]$ pyruvate has been applied in preclinical models and has shown promising results for monitoring brain tumor growth and assessing response to
Fig. 1 Diagram of observable metabolic pathways using hyperpolarized $\left[1-{ }^{13} \mathrm{C}\right]$ pyruvate (red) and $\left[2-{ }^{13} \mathrm{C}\right]$ pyruvate (green) in the brain metabolism. $\left[1-{ }^{13} \mathrm{C}\right]$ converts to $\left[1-{ }^{13} \mathrm{C}\right]$ lactate via lactate dehydrogenase (LDH), $\left[1-{ }^{13} \mathrm{C}\right]$ alanine via alanine transaminase (ALT) in subcutaneous tissue and muscle outside the brain [43], and ${ }^{13} \mathrm{C}$ carbon dioxide $\left({ }^{13} \mathrm{CO}_{2}\right)$ via pyruvate dehydrogenase (PDH) within the mitochondria, which is then catalyzed to ${ }^{13} \mathrm{C}$-bicarbonate by carbonic anhydrase (CA). $\left[2-{ }^{13} \mathrm{C}\right]$ pyruvate provides direct measurements of $\left[2-{ }^{13} \mathrm{C}\right]$ lactate, $\left[5-{ }^{13} \mathrm{C}\right]$ glutamate, and other TCA intermediates

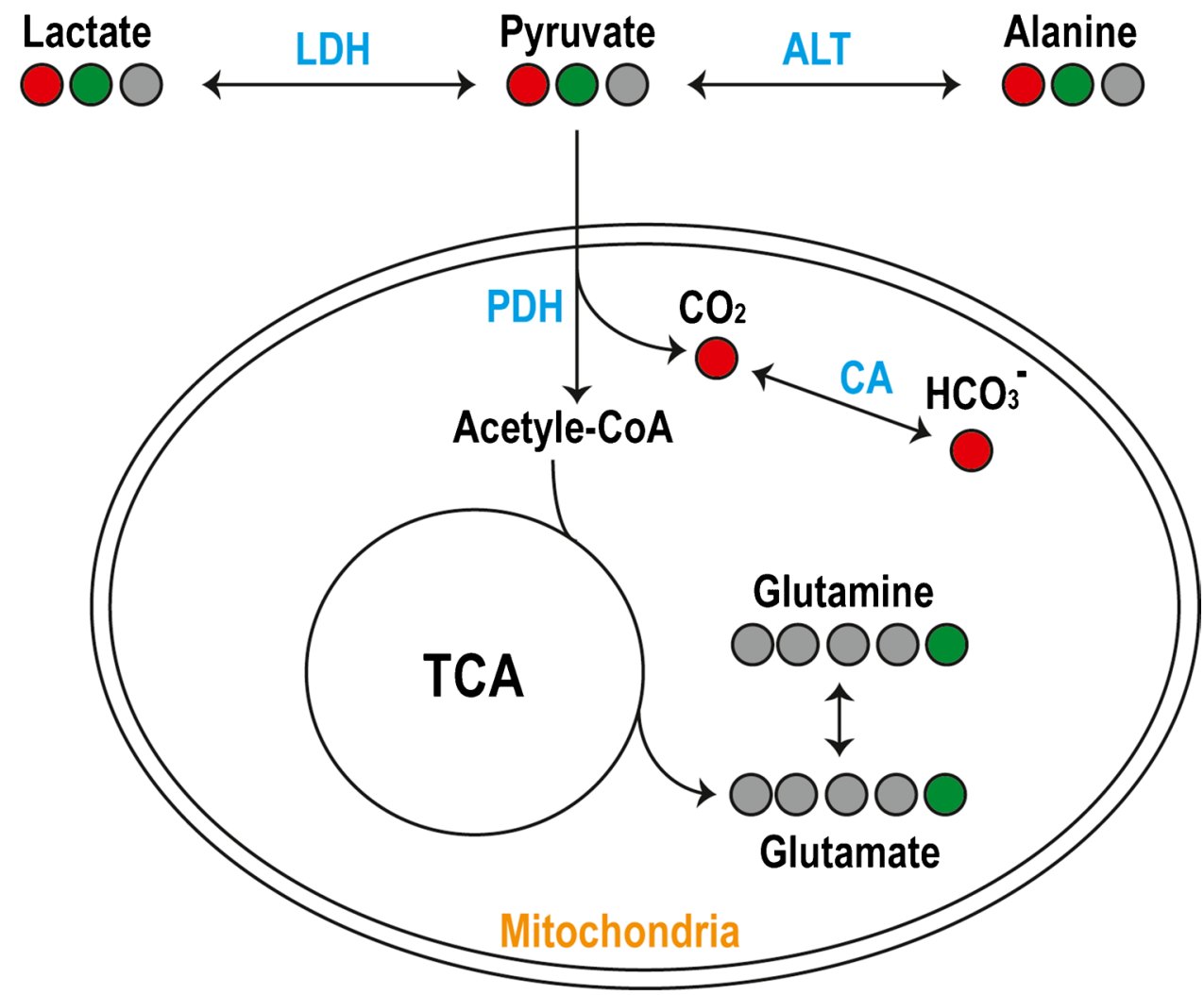


therapy [26-31], assessing aerobic metabolic abnormality and monitoring treatment in traumatic brain injury (TBI) $[32,33]$, and detecting neuroinflammation in multiple sclerosis [34]. However, the enhanced signal decays as polarization returns to the natural equilibrium after 1-2 min. Similar to the half-life in PET, the T1 relaxation time of the probes determines how long the signal lasts, which in turn, requires fast acquisitions to obtain the dynamic conversion before the signal decays away. The $\mathrm{T} 1$ relaxation times of commonly used $\mathrm{HP}{ }^{13} \mathrm{C}$ probes were summarized in Wang et al. [24]. Of these probes, $\left[1-{ }^{13} \mathrm{C}\right]$ pyruvate has a relatively long $\mathrm{T} 1$ relaxation time, $\sim 60 \mathrm{~s}$. Additionally, due to the nature of hyperpolarization, the signal can only be used once, creating a need for creative acquisition schemes to fully utilize the available signal.

PET radiolabeled tracers have high sensitivity, but their utility for metabolic imaging is limited by the absence of chemical information - that is, PET can detect tracer uptake but cannot resolve metabolic conversion. The added concerns related to radiation dose from the injected tracer, particularly for studies in healthy subjects, further limit its utilization in neuroscience studies. ${ }^{1} \mathrm{H}$ MRS provides chemical information by directly resolving metabolites, providing insight into the brain's steady-state metabolism. However, it is limited by the low concentration of endogenous metabolites [35], resulting in coarse resolution and long acquisition times that acquire a steady-state snapshot of metabolism that is not fully representative of dynamic processes [36]. HP ${ }^{13} \mathrm{C}$ MR metabolic imaging provides dynamic information of metabolic processes and complements both PET and ${ }^{1} \mathrm{H}$ MRS's major weaknesses, by obtaining metabolic dynamic conversions [37] on a rapid timescale.

\section{Considerations in translating dynamic hyperpolarized ${ }^{13} \mathrm{C}$ metabolic imaging to clinical brain studies}

While cellular and preclinical $\mathrm{HP}{ }^{13} \mathrm{C}$ studies have been used to inform and aid in the design of clinical translation, their results are impacted by the use of anesthesia, which is known to alter hemodynamics, metabolism, and functional connectivity $[38,39]$, and other physiological and evolutionary differences. Additionally, for brain studies, the blood-brain barrier (BBB), an anatomic and physiologic barrier that protects the brain by tightly regulating the passage of molecules, is an important factor that needs to be considered. Small molecules, such as glucose and amino acids, can cross the cell membrane through diffusion and transporters. Pyruvate transport and uptake across the BBB in anesthetized animals have been shown to be rate-limiting [40]. These questions can only be addressed in human brain studies, which further encourage clinical translation. The first human HP $\left[1-{ }^{13} \mathrm{C}\right]$ pyruvate study was reported at the University of California San Francisco in 2013 on a cohort of patients with prostate cancer [41]. The first human brain studies published in 2018 using $\left[1-{ }^{13} \mathrm{C}\right]$ pyruvate have established the safety and feasibility of the imaging agent in patients with brain tumors [42, 43]. The first study [41] was accomplished using a prototype polarizer in a cleanroom to provide the sterile solution for human use, while new clinical polarizers, SPINlab (GE Healthcare), are now commercially available and have been installed in more than 20 academic medical centers worldwide for human studies.

Previous review articles have summarized key factors required for clinically translating this novel imaging method $[24,44,45]$. The time sensitivity and one-use magnetization associated with HP experiments mean that the development of acquisition procedures, radio-frequency $(\mathrm{RF})$ hardware design, and sequences used to acquire $\mathrm{HP}^{13} \mathrm{C}$ data are critical. The procedures include the preparation of the pyruvate using a pharmacy kit (containing a sterile fluid path (Fig. 2) and reagents) used for preparing sterile ${ }^{13} \mathrm{C}$ probes, hyperpolarization, and quality control (QC) before the injection. The steps for QC [46], including sterilizing the polarizer components and verifying the sample $\mathrm{pH}$, temperature, volume, concentration, and polarization, have been optimized to decrease the time to injection from 88 (74 114) (mean ( $\mathrm{min}$ $\max )$ ) [43] to 58 (49 83) s [46] in patients with glioma. Several ${ }^{13} \mathrm{C}$ RF multichannel coils have been developed to obtain ${ }^{13} \mathrm{C}$ signals with distinct advantages $[47,48]$. The choice of use could depend on the regions of interest, head size, and the acquisition methods (e.g., parallel imaging). However, they are single-tuned and require two separate examinations to acquire diagnostic-quality ${ }^{1} \mathrm{H}$ MRI data, extending the total time that the patient needs to be in the scanner and inefficiently allocating resources. A dual-tuned ${ }^{13} \mathrm{C} /{ }^{1} \mathrm{H}$ coil was recently used in an integrated ${ }^{13} \mathrm{C} /{ }^{1} \mathrm{H}$ examination [46] and demonstrated decent data quality and improved patient comfort. Compared to the preclinical studies that use small fields of view (FOVs), dynamic $\mathrm{HP}{ }^{13} \mathrm{C}$ imaging with volumetric coverage and imaging of human brains require far greater FOV coverage. A number of pulse sequences have been developed, such as echo planar spectroscopic imaging (EPSI) [43, 49], frequency-specific echo planar imaging (EPI) [50-53], and IDEAL (iterative decomposition with echo asymmetry and least squares estimation) [54, 55], and discussed in a recent review article [56]. The dynamic data are then reconstructed [45, 55, 57], combined [58] (when acquired with multichannel RF coils), and summed or fitted with a kinetic model to estimate the rates of conversion, for example, from pyruvate to lactate $\left(k_{\mathrm{PL}}\right)$ and from pyruvate to bicarbonate $\left(k_{\mathrm{PB}}\right)$ for $\left[1-{ }^{13} \mathrm{C}\right]$ pyruvate $[55,59]$.

$\mathrm{HP}^{13} \mathrm{C}$ probes that have been used for human brain are $\left[1-{ }^{13} \mathrm{C}\right]$ pyruvate $[43,46,47,55,60,61]$ and $\left[2-{ }^{13} \mathrm{C}\right]$ pyruvate [62], with the carbon in the $\mathrm{C} 1$ or $\mathrm{C} 2$ position labeled 


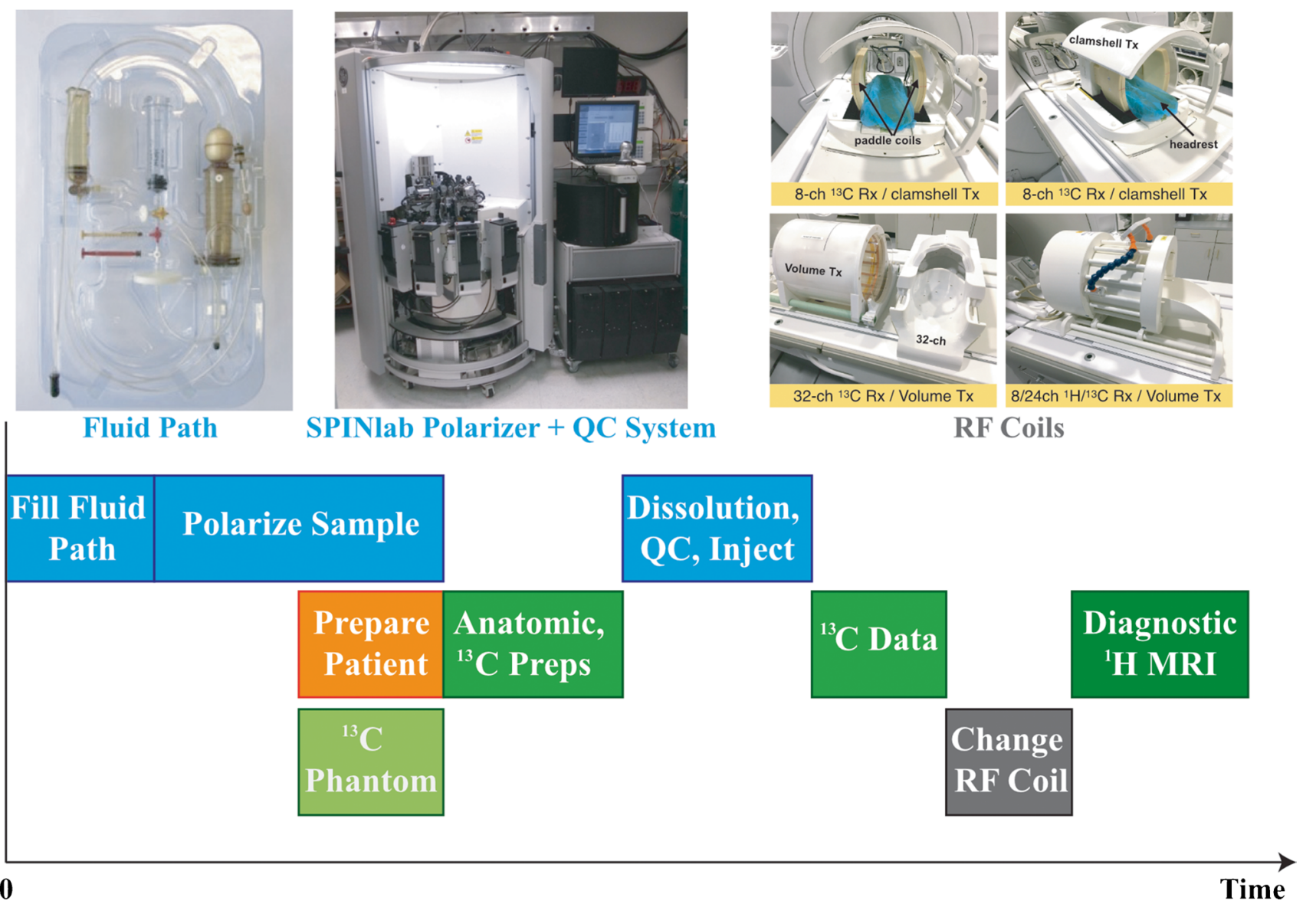

Fig. 2 Schematic describing the logistics associated with preparing the ${ }^{13} \mathrm{C}$ sample, scanner, and patient. The example of RF coils was from Autry et al. [46]

with ${ }^{13} \mathrm{C}$. From these studies, the suggested logistics for the preparation of the imaging agent and data acquisition for patient studies are represented in Fig. 2. The fluid path is filled with pyruvate by a licensed pharmacist and placed in the SPINlab system to be polarized for approximately $2 \mathrm{~h}$. Concurrently, the patient will be prepared, their vital signs evaluated, and an intravenous line inserted; while the scanner, RF coil, and pulse sequence to be verified with a phantom scan. Once the polarization and phantom scan have been completed, the patient will be positioned in the scanner and reference anatomic ${ }^{1} \mathrm{H}$ images obtained using the body coil or dual-tuned ${ }^{13} \mathrm{C} /{ }^{1} \mathrm{H}$ coil. Once the pre-exam checklist is completed, the sample dissolution will be initiated, QC performed, and the resulting solution captured in the syringe. The syringe will be rapidly transported into the scan room; with the pharmacist signaling approval, the ${ }^{13} \mathrm{C}$ tagged compound will be injected into the patient using an automatic injector. Acquisition of the ${ }^{13} \mathrm{C}$ data will begin at time of injection or shortly after the completion of saline flush. The remaining ${ }^{1} \mathrm{H}$ imaging sequences for clinical use will be obtained to complete the examination using the dual-tuned ${ }^{13} \mathrm{C} /{ }^{1} \mathrm{H}$ coil or after switching to a standard ${ }^{1} \mathrm{H}$ coil.

\section{Emerging human brain applications of dynamic hyperpolarized ${ }^{13} \mathrm{C}$ metabolic imaging}

For brain studies, HP $\left[1-{ }^{13} \mathrm{C}\right]$ pyruvate has been applied in healthy controls [55, 60]; patients with glioma [42, 43, 46], brain metastasis [42, 63], and TBI [64]; and pediatric patients with CNS tumors [65]. In the following section, we will discuss these most recent clinical applications.

Understanding metabolism in the normal brain is essential to improving our understanding of the biological processes in the diseased brain. The recent healthy volunteer studies exhibited higher $\left[1-{ }^{13} \mathrm{C}\right]$ pyruvate, $\left[1-{ }^{13} \mathrm{C}\right]$ lactate, and ${ }^{13} \mathrm{C}$-bicarbonate in the gray matter compared to white matter $[55,60]$ and regional variations across the subjects [60]. Establishing the reproducibility of data acquisition, processing, and analysis methods is especially important for providing results that are used for the clinical management 
of patients. Two volunteers received repeated acquisitions varying from $30 \mathrm{~min}$ to 107 days and demonstrated consistency in $k_{\mathrm{PL}}$ and $k_{\mathrm{PB}}$ values within the white matter [46]. More recently, a study reported a significant decrease in lactate production associated with age from 28 healthy human subjects [61], providing similar results of the reduction in nonoxidative metabolism with aging in studies using PET agents [66]. This suggests a new application for $\mathrm{HP}^{13} \mathrm{C}$ metabolic imaging to investigate age related metabolic changes in the brain.

The fundamental basis of using $\left[1-{ }^{13} \mathrm{C}\right]$ lactate in brain tumors relies on the well-known Warburg effect, excessive production of lactate (aerobic glycolysis) in tumor cells [67]. The initial studies in brain tumors were acquired using single-slice dynamic EPSI acquisition [42, 43]. The results in patients with stable disease showed that the ratios of ${ }^{13} \mathrm{C}$-bicarbonate to $\left[1-{ }^{13} \mathrm{C}\right]$ pyruvate (bicarbonate/pyruvate) and $\left[1-{ }^{13} \mathrm{C}\right]$ lactate to $\left[1-{ }^{13} \mathrm{C}\right]$ pyruvate (lactate/pyruvate) were lower in the $\mathrm{T} 2$ lesion than those in the normal-appearing brain, with low levels of bicarbonate/pyruvate and elevated lactate/pyruvate ratio in progressive disease [43]. With the development of improved acquisition methods, e.g., multislice dynamic EPI acquisition [51], it is possible to longitudinally track the metabolic changes in the regions of interest. Autry et al. [46] reported serial $\mathrm{HP}{ }^{13} \mathrm{C}$ MR examinations in patients with recurrent glioma. The conversion rates $\left(k_{\mathrm{PL}}, k_{\mathrm{PB}}\right)$ within the normal-appearing white matter in the patients who received standard of care treatment were similar to those in healthy controls. Patients with tumor progression showed relatively higher conversion rates to $\left[1-{ }^{13} \mathrm{C}\right]$ lactate $\left(k_{\mathrm{PL}}\right)$ in the contrast-enhancing and non-enhancing lesions relative to those in the normal-appearing white matter. In a patient who had been followed for 512 days with $9 \mathrm{HP}{ }^{13} \mathrm{C}$ examinations, $k_{\mathrm{PL}}$ increased in the lesion when new lesions developed (Fig. 3). These encouraging results demonstrate the utility of $\mathrm{HP}{ }^{13} \mathrm{C}$ imaging for evaluating patients with glioma.

Other $\left[1-{ }^{13} \mathrm{C}\right]$ pyruvate $\mathrm{HP}{ }^{13} \mathrm{C}$ MR metabolic brain imaging studies also include (1) safety and feasibility study in pediatric patients with CNS tumors (diffuse intrinsic pontine glioma, DIPG; craniopharyngioma; medulloblastoma) [65]. This study demonstrated preliminary safety profile in 6 patients at dosages of 0.34 and $0.43 \mathrm{~mL} / \mathrm{kg}$. The latter is an adult dosage that was determined in an initial clinical trial [41]. (2) Initial study in patients with brain metastasis found varied $\left[1-{ }^{13} \mathrm{C}\right] \mathrm{lac}-$ tate production in the lesion [42]. Metabolic heterogeneity in brain metastasis was confirmed in a recent study, and progression was associated with the highest lactate $z$-scores, converted from the mean and standard deviation of ${ }^{13} \mathrm{C}$ lactate signals for each region [63] (Fig. 4). (3) HP $\left[1-{ }^{13} \mathrm{C}\right]$ pyruvate MR metabolic imaging has been applied to two patients with mild acute TBI [64]. One patient had increased $\left[1-{ }^{13} \mathrm{C}\right]$ lactate over the total ${ }^{13} \mathrm{C}$-labeled metabolite signals (TC) at the injury site, and both patients had decreased ${ }^{13} \mathrm{C}$-bicarbonate over TC in the injured hemisphere. This is the first study demonstrating the feasibility of using dynamic HP $\left[1-{ }^{13} \mathrm{C}\right]$ pyruvate to detect altered downstream glucose metabolism and mitochondrial dysfunction in TBI.

While ${ }^{13} \mathrm{C}$-bicarbonate converted from $\left[1-{ }^{13} \mathrm{C}\right]$ pyruvate has been used as a surrogate biomarker for mitochondria oxidative metabolism, it is nonspecific. Its signal intensity is altered by changes in $\mathrm{pH}$ catalyzed by CA $[68,69]$. Alternatively, $\left[2-{ }^{13} \mathrm{C}\right]$ pyruvate can be incorporated into the TCA cycle (tricarboxylic acid cycle) intermediates rather than being released as ${ }^{13} \mathrm{CO}_{2}$, providing direct measurements of $\left[5-{ }^{13} \mathrm{C}\right]$ glutamate, and other TCA intermediates (Fig. 1). Thus, $\left[2-{ }^{13} \mathrm{C}\right]$ pyruvate allows simultaneous measurement of glycolysis through its conversion to $\left[2-{ }^{13} \mathrm{C}\right]$ lactate and oxidative metabolism to $\left[5-{ }^{13} \mathrm{C}\right]$ glutamate, making it an attractive substrate for evaluating cancer and neurologic diseases. However, there are technical challenges in obtaining these metabolites over large spectral bandwidth in a short acquisition window (short $\mathrm{T} 1, \sim 40 \mathrm{~s}$ ). Initial HP $\left[2-{ }^{13} \mathrm{C}\right]$ pyruvate studies were performed on healthy volunteers using nonlocalized dynamic 1D spectroscopy [62]. Sufficient polarization was achieved to observe the TCA cycle metabolites $\left[5-{ }^{13} \mathrm{C}\right]$ glutamate and $\left[1-{ }^{13} \mathrm{C}\right]$ citrate, along with $\left[2-{ }^{13} \mathrm{C}\right]$ lactate. Whole-brain $k_{\mathrm{PL}}$ values derived from $\left[2-{ }^{13} \mathrm{C}\right]$ pyruvate were consistent with those from $\left[1-{ }^{13} \mathrm{C}\right]$ pyruvate. In a preliminary study with two patients with IDH mutant glioma using 2D chemical shift imaging (non-dynamic), a reduction in the ratio of $\left[5-{ }^{13} \mathrm{C}\right]$ glutamate/[2- $\left.{ }^{13} \mathrm{C}\right]$ pyruvate was seen in the $\mathrm{T} 2$ lesion compared to the contralateral normal brain, which is consistent with known metabolic reprogramming in IDH mutation [70]. Volumetric, dynamic HP $\left[2-{ }^{13} \mathrm{C}\right]$ pyruvate EPI acquisitions were recently developed and applied to healthy volunteers and patients with glioma [71], which provides the feasibility of using this probe to assess response to therapy for patients with glioma [72-74].

A few other probes have been applied in preclinical models but have not been translated for clinical applications. These candidates in tumors $[24,75]$ and neurologic diseases [76, 77] have been discussed previously. Similar to PET probes, obtaining US Food and Drug Administration (FDA) regulatory approval is required before starting human studies.

\section{Challenges in technology of hyperpolarized ${ }^{13} \mathrm{C}$ metabolic imaging}

With the promising metabolic assessments enabled by HP

${ }^{13} \mathrm{C}$ MR metabolic imaging, it is increasingly being used in various human organ systems. These advancements are 
b

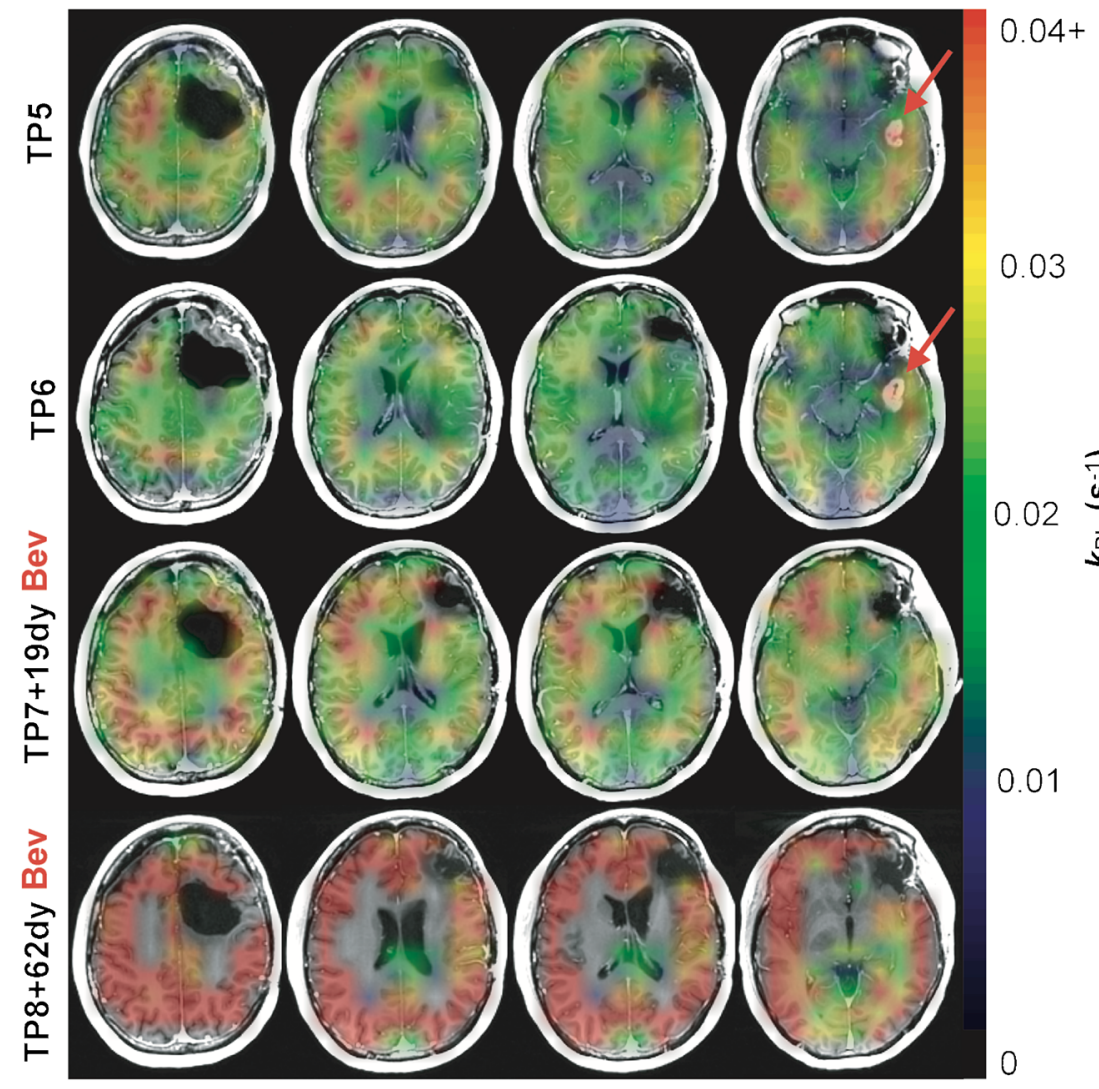

Pre-bevacizumab

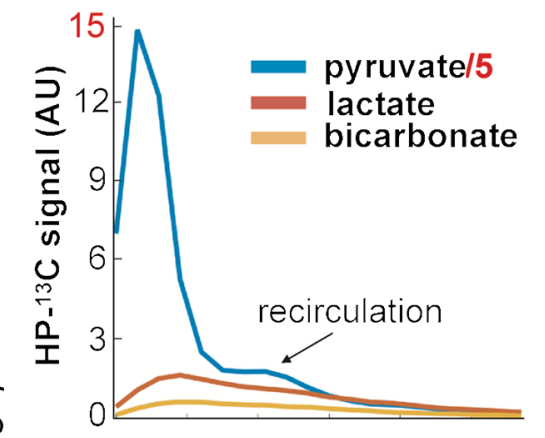

年

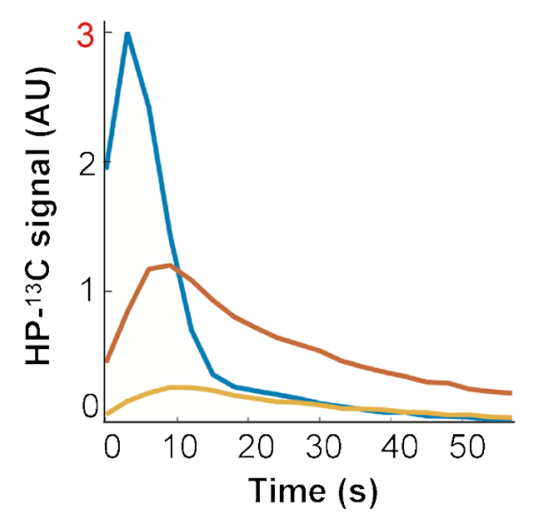

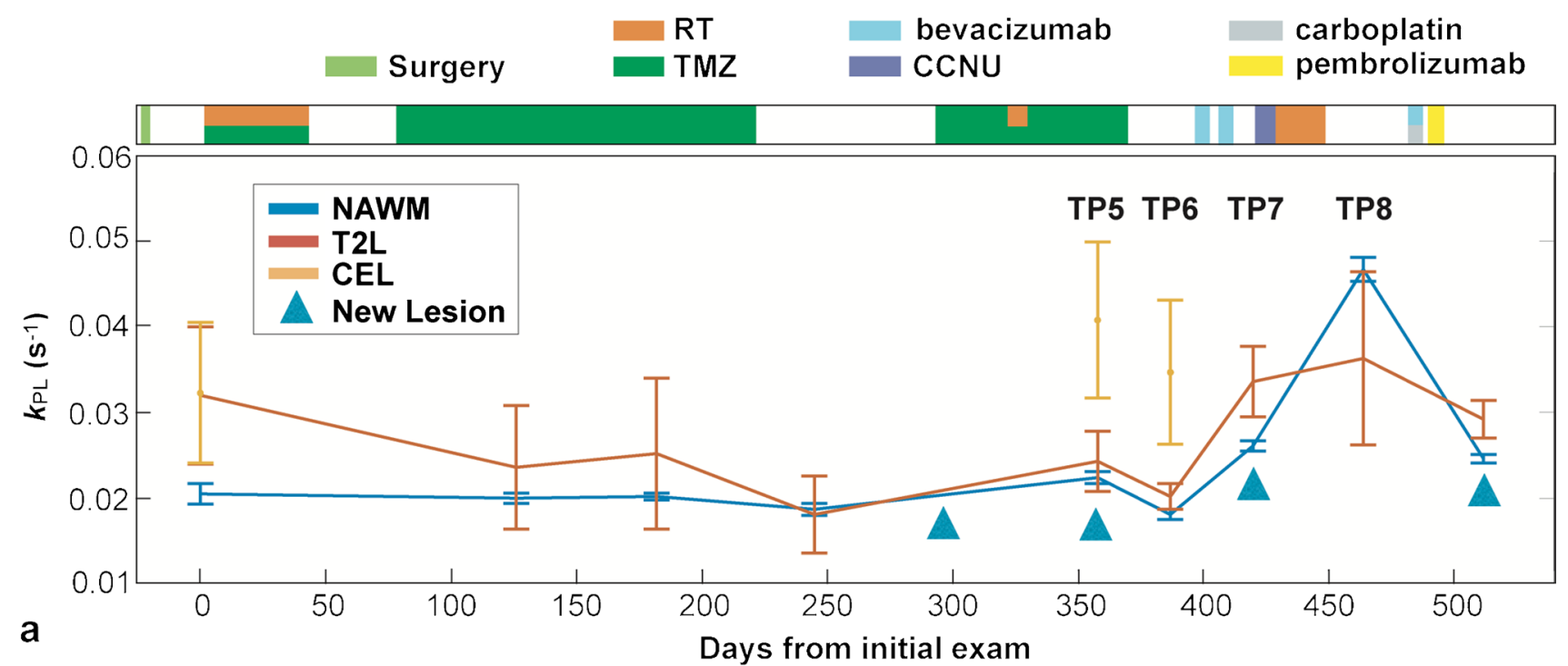

Fig. 3 Serial $k_{\mathrm{PL}}$ within normal-appearing white matter and anatomic lesions from a patient with IDH mutant glioblastoma over 9 scans spanning 512 days (a). $k_{\mathrm{PL}}$ increased in the lesion when new lesions developed. During time points TP5-TP8, the emergence of a new gadolinium-enhancing lesion with elevated $k_{\mathrm{PL}}$ (red arrows) disap- peared following treatment with bevacizumab and subsequent global elevation of $k_{\mathrm{PL}}(\mathbf{b})$. The dynamic data showed that overall lower ${ }^{13} \mathrm{C}$ signals after treating with bevacizumab, but the conversion rate to $\left[1-{ }^{13} \mathrm{C}\right]$ lactate was increased (c). Figure adapted from Autry et al. [46] 


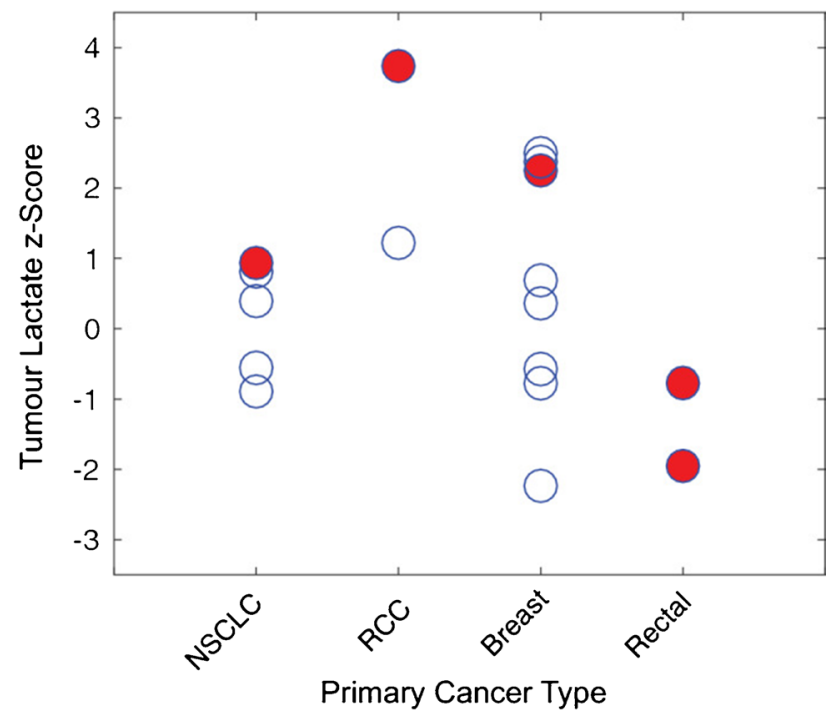

Fig. 4 Lactate $z$-scores of new lesions from 11 patients with intracranial metastases. The red circles represent the lesions that progressed at 6 months of post-treatment follow-up or at the time of death, while these open circles are stable or responding lesions. Figure adapted from Lee et al. [63]

hindered by the array of required specialized resources, including the pharmacy resource, SPINlab polarizer, ${ }^{13} \mathrm{C}$ $\mathrm{RF}$ coils, and a team of engineers and scientists, that are mandatory to perform such study.

\section{Hardware}

Currently, the SPINlab instrument can simultaneously polarize up to four samples with regeneration after 12 samples per day. This limits the number of patients that can be performed. With each $\mathrm{HP}{ }^{13} \mathrm{C}$ injection requiring a sterile fluid path, the total cost is comparable to that of PET study despite short acquisition time. There are ongoing efforts (academically and by GE Healthcare) to reduce the cost and allowing polarizing more samples are needed for further clinical translation. Additionally, as previously described, the choice of receive coil to detect ${ }^{13} \mathrm{C}$ signals will impact the quality of data as well as patient handling.

\section{Acquisition}

Although remarkable development has been achieved on acquisition methods, majority of brain $\mathrm{HP}{ }^{13} \mathrm{C}$-pyruvate data are acquired at the spatial resolution of $1.5 \times 1.5 \times 1.5$ $\mathrm{cm}^{3}$ with $3 \mathrm{~s}$ temporal resolution, which is not sufficient to capture spatial heterogeneity for all brain studies. Improvements to reduce the time to injection with optimized sample preparation, use long $\mathrm{T} 1$ probes, or further optimize fast metabolic imaging methods [56] will provide better signal-to-time ratio (SNR) to improve spatial resolution. A novel multi-resolution EPI sequence with an in-plane resolution of $7.5 \times 7.5 \mathrm{~mm}$ for pyruvate and $15 \times 15 \mathrm{~mm}$ for lactate has recently been developed and demonstrated significantly reduced signal bleeding in from the periphery [52]. This is particularly for the regions around the superior sagittal sinus and white matter with high pyruvate signals from highly perfused regions [78]. For further improvements in SNR, image denoising approaches have recently been shown to increase the sensitivity of $\mathrm{HP}^{13} \mathrm{C}$ studies. Techniques based on higher-order singular value decomposition (SVD), a generation of multidimensional matrix SVD, have significantly improved SNR for $\left[1-{ }^{13} \mathrm{C}\right]$ lactate and ${ }^{13} \mathrm{C}$-bicarbonate $[79,80]$. Figure 5 illustrates an example using tensor rank truncation-image enhancement, which applies higher-order SVD followed by a lowrank approximation. With innovative acquisition and postprocessing methods, it is possible to achieve the spatial resolution that is similar to PET images or fMRI. It is worth noting that many of the institutions use homegrown
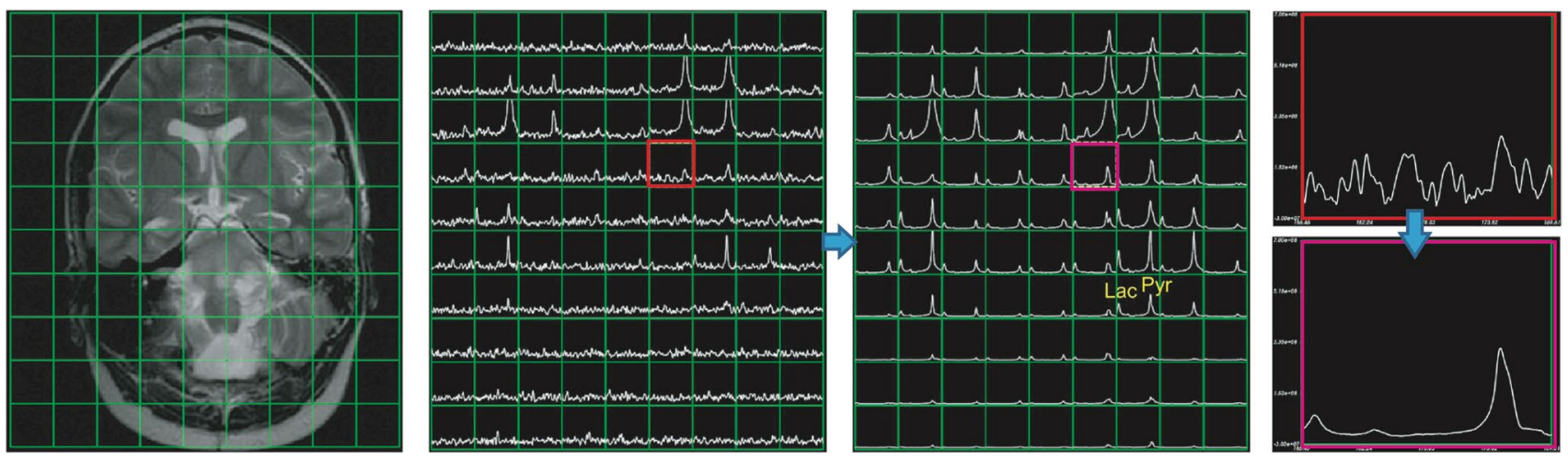

Fig. 5 The spectra at $15 \mathrm{~s}$ from the start of data acquisition using 2D dynamic EPSI from a 12-year-old patient with DIPG. Whitened singular value decomposition channel sum and tensor rank truncation- image enhancement significantly improved the SNR. Figure adapted from Chen et al. [79] 
acquisition schemes and processing methods. To conduct large-scale studies, on the scale of the Human Connectome Project, further standardization will be needed to ensure consistency and interpretation of the metabolic data.

\section{Physiology}

An important factor that decides the signal quality is the tracer delivery-flow, perfusion, and active transport. The quantity delivered will directly impact the amount of measured tracer compound and converted metabolites. For example, DIPG is a tumor located in the weakly perfused brain stem. Higher ratios of $\left[1-{ }^{13} \mathrm{C}\right]$ lactate to $\left[1-{ }^{13} \mathrm{C}\right]$ pyruvate were seen in the lesion while $\left[1-{ }^{13} \mathrm{C}\right]$ pyruvate signal was relatively low [65]. In another case shown in Fig. 3, the patient had the enhancing lesion resolved after receiving the anti-angiogenic agent bevacizumab, along with the global increase of $k_{\mathrm{PL}}$ within the normal-appearing white matter [46]. The dynamic data showed that overall lower ${ }^{13} \mathrm{C}$ signals after treating with bevacizumab, but the conversion rate to $\left[1-{ }^{13} \mathrm{C}\right]$ lactate was increased. These two cases suggested that reduced pyruvate delivery either from low perfusion or reduced vascular permeability causes rapid conversion to its downstream metabolites. Since $\left[1-{ }^{13} \mathrm{C}\right]$ pyruvate enters the blood-brain barrier (BBB) via a monocarboxylate transporter, this effect could be due to increased transportation. The role of MCT has been found to be critical for detecting HP $\left[1-{ }^{13} \mathrm{C}\right]$ pyruvate-to- $\left[1-{ }^{13} \mathrm{C}\right]$ lactate [81]. Both MCT1 and MCT4 were significantly increased in IDH mutant glioma and glioblastoma [82, 83]. Besides, the conversion measured also depends on several factors such as NADH levels and LDH activity [25].

\section{Conclusion and perspectives}

This review has highlighted the promising technology of $\mathrm{HP}{ }^{13} \mathrm{C}$ MRI to acquire dynamic metabolic information, which are complementary to existing anatomic and functional imaging methods. As a technology undergoing rapid development, there are significant hardware, software, and physiological related challenges. Resolving these challenges will be key to wider adoption for clinical diagnostics and measuring early treatment response as well as biological studies.

Acknowledgements We acknowledge the UCSF Hyperpolarized Technology Resource Center.

Funding This work is supported by NIH grants P41 EB013598, P50 CA097257, and P01 CA118816.

\section{Declarations}

Conflict of interest The authors declare no competing interests.

Ethics approval This article does not contain any studies with human participants or animals performed by any of the authors.

Open Access This article is licensed under a Creative Commons Attribution 4.0 International License, which permits use, sharing, adaptation, distribution and reproduction in any medium or format, as long as you give appropriate credit to the original author(s) and the source, provide a link to the Creative Commons licence, and indicate if changes were made. The images or other third party material in this article are included in the article's Creative Commons licence, unless indicated otherwise in a credit line to the material. If material is not included in the article's Creative Commons licence and your intended use is not permitted by statutory regulation or exceeds the permitted use, you will need to obtain permission directly from the copyright holder. To view a copy of this licence, visit http://creativecommons.org/licenses/by/4.0/.

\section{References}

1. Barkovich AJ, Miller SP, Bartha A, Newton N, Hamrick SE, Mukherjee P, et al. MR imaging, MR spectroscopy, and diffusion tensor imaging of sequential studies in neonates with encephalopathy. AJNR Am J Neuroradiol. 2006;27:533-47.

2. Xu D, Bonifacio SL, Charlton NN, C PV, Lu Y, Ferriero DM, et al. MR spectroscopy of normative premature newborns. J Mag Resonance Imaging. 2011;33:306-11.

3. Nelson SJ. Analysis of volume MRI and MR spectroscopic imaging data for the evaluation of patients with brain tumors. Magn Reson Med. 2001;46:228-39.

4. Nelson SJ. Multivoxel magnetic resonance spectroscopy of brain tumors. Mol Cancer Ther. 2003;2:497-507.

5. Hasler G, van der Veen JW, Tumonis T, Meyers N, Shen J, Drevets WC. Reduced prefrontal glutamate/glutamine and gamma-aminobutyric acid levels in major depression determined using proton magnetic resonance spectroscopy. Arch Gen Psychiatry. 2007;64:193-200. https://doi.org/10.1001/archpsyc. 64.2.193.

6. Li Y, Jakary A, Gillung E, Eisendrath S, Nelson SJ, Mukherjee $\mathrm{P}$, et al. Evaluating metabolites in patients with major depressive disorder who received mindfulness-based cognitive therapy and healthy controls using short echo MRSI at 7 Tesla. MAGMA. 2016;29:523-33. https://doi.org/10.1007/s10334-016-0526-7.

7. Doelken MT, Hammen T, Bogner W, Mennecke A, Stadlbauer A, Boettcher U, et al. Alterations of intracerebral gamma-aminobutyric acid (GABA) levels by titration with levetiracetam in patients with focal epilepsies. Epilepsia. 2010;51:1477-82. https://doi.org/10.1111/j.1528-1167.2010.02544.x.

8. Andronesi OC, Rapalino O, Gerstner E, Chi A, Batchelor TT, Cahill DP, et al. Detection of oncogenic IDH1 mutations using magnetic resonance spectroscopy of 2-hydroxyglutarate. J Clin Investig. 2013;123:3659-63. https://doi.org/10.1172/JCI67229.

9. Choi C, Ganji SK, DeBerardinis RJ, Hatanpaa KJ, Rakheja D, Kovacs Z, et al. 2-hydroxyglutarate detection by magnetic resonance spectroscopy in IDH-mutated patients with gliomas. Nat Med. 2012;18:624-9. https://doi.org/10.1038/nm.2682.

10. Emir UE, Larkin SJ, de Pennington N, Voets N, Plaha P, Stacey R, et al. Noninvasive quantification of 2-hydroxyglutarate in human gliomas with IDH1 and IDH2 mutations. Cancer Res. 2016;76:43-9. https://doi.org/10.1158/0008-5472.CAN-15-0934. 
11. Viswanath P, Chaumeil MM, Ronen SM. Molecular imaging of metabolic reprograming in mutant IDH cells. Front Oncol. 2016;6:60. https://doi.org/10.3389/fonc.2016.00060.

12. Dang L, White DW, Gross S, Bennett BD, Bittinger MA, Driggers EM, et al. Cancer-associated IDH1 mutations produce 2-hydroxyglutarate. Nature. 2009;462:739-44. https://doi.org/ 10.1038/nature08617.

13. Judenhofer MS, Wehrl HF, Newport DF, Catana C, Siegel SB, Becker M, et al. Simultaneous PET-MRI: a new approach for functional and morphological imaging. Nat Med. 2008;14:45965. https://doi.org/10.1038/nm1700.

14. Galldiks N, Lohmann P, Albert NL, Tonn JC, Langen KJ. Current status of PET imaging in neuro-oncology. Neurooncol Adv. 2019;1:vdz010. https://doi.org/10.1093/noajnl/vdz010.

15. Brown RK, Bohnen NI, Wong KK, Minoshima S, Frey KA. Brain PET in suspected dementia: patterns of altered FDG metabolism. Radiographics. 2014;34:684-701. https://doi.org/ 10.1148/rg.343135065.

16. Sarikaya I, Sarikaya A, Elgazzar AH. Current status of (18)F-FDG PET brain imaging in patients with dementia. J Nucl Med Technol. 2018;46:362-7. https://doi.org/10.2967/jnmt.118.210237.

17. Rathore C, Dickson JC, Teotonio R, Ell P, Duncan JS. The utility of 18F-fluorodeoxyglucose PET (FDG PET) in epilepsy surgery. Epilepsy Res. 2014;108:1306-14. https://doi.org/10. 1016/j.eplepsyres.2014.06.012.

18. Carne RP, O'Brien TJ, Kilpatrick CJ, Macgregor LR, Litewka L, Hicks RJ, et al. "MRI-negative PET-positive" temporal lobe epilepsy (TLE) and mesial TLE differ with quantitative MRI and PET: a case control study. BMC Neurol. 2007;7:16. https://doi. org/10.1186/1471-2377-7-16.

19. Lamusuo S, Jutila L, Ylinen A, Kalviainen R, Mervaala E, Haaparanta M, et al. [18F]FDG-PET reveals temporal hypometabolism in patients with temporal lobe epilepsy even when quantitative MRI and histopathological analysis show only mild hippocampal damage. Arch Neurol. 2001;58:933-9. https://doi. org/10.1001/archneur.58.6.933.

20. Ardenkjaer-Larsen JH, Fridlund B, Gram A, Hansson G, Hansson $\mathrm{L}$, Lerche $\mathrm{MH}$, et al. Increase in signal-to-noise ratio of $>$ 10,000 times in liquid-state NMR. Proc Natl Acad Sci USA. 2003;100:10158-63. https://doi.org/10.1073/pnas.1733835100.

21. Golman K, Ardenkjaer-Larsen JH, Petersson JS, Mansson S, Leunbach I. Molecular imaging with endogenous substances. Proc Natl Acad Sci USA. 2003;100:10435-9. https://doi.org/10.1073/ pnas. 1733836100 .

22. Golman K, Zandt RI, Lerche M, Pehrson R, Ardenkjaer-Larsen $\mathrm{JH}$. Metabolic imaging by hyperpolarized $13 \mathrm{C}$ magnetic resonance imaging for in vivo tumor diagnosis. Cancer Res. 2006;66:1085560. https://doi.org/10.1158/0008-5472.CAN-06-2564.

23. Mishkovsky M, Anderson B, Karlsson M, Lerche MH, Sherry $\mathrm{AD}$, Gruetter R, et al. Measuring glucose cerebral metabolism in the healthy mouse using hyperpolarized (13)C magnetic resonance. Sci Rep. 2017;7:11719. https://doi.org/10.1038/ s41598-017-12086-Z.

24. Wang ZJ, Ohliger MA, Larson PEZ, Gordon JW, Bok RA, Slater J, et al. Hyperpolarized (13)C MRI: state of the art and future directions. Radiology. 2019;291:273-84. https://doi.org/10.1148/ radiol.2019182391.

25. Hurd RE, Yen YF, Tropp J, Pfefferbaum A, Spielman DM, Mayer D. Cerebral dynamics and metabolism of hyperpolarized [1-(13) C]pyruvate using time-resolved MR spectroscopic imaging. J Cerebral Blood Flow Metabol. 2010;30:1734-41. https://doi.org/10. 1038/jcbfm.2010.93.

26. Nelson SJ, Vigneron D, Kurhanewicz J, Chen A, Bok R, Hurd R. DNP-hyperpolarized $\mathrm{C}$ magnetic resonance metabolic imaging for cancer applications. Appl Magn Resonance. 2008;34:533-44. https://doi.org/10.1007/s00723-008-0136-2.
27. Park I, Larson PE, Zierhut ML, Hu S, Bok R, Ozawa T, et al. Hyperpolarized 13C magnetic resonance metabolic imaging: application to brain tumors. Neuro Oncol. 2010;12:133-44. https://doi.org/10.1093/neuonc/nop043.

28. Park I, Bok R, Ozawa T, Phillips JJ, James CD, Vigneron DB, et al. Detection of early response to temozolomide treatment in brain tumors using hyperpolarized 13C MR metabolic imaging. J Magn Resonance Imaging. 2011;33:1284-90. https://doi.org/10. 1002/jmri.22563.

29. Chaumeil MM, Ozawa T, Park I, Scott K, James CD, Nelson SJ, et al. Hyperpolarized 13C MR spectroscopic imaging can be used to monitor everolimus treatment in vivo in an orthotopic rodent model of glioblastoma. Neuroimage. 2012;59:193-201. https:// doi.org/10.1016/j.neuroimage.2011.07.034.

30. Park JM, Spielman DM, Josan S, Jang T, Merchant M, Hurd RE, et al. Hyperpolarized (13)C-lactate to (13)C-bicarbonate ratio as a biomarker for monitoring the acute response of anti-vascular endothelial growth factor (anti-VEGF) treatment. NMR Biomed. 2016;29:650-9. https://doi.org/10.1002/nbm.3509.

31. Datta K, Lauritzen MH, Merchant M, Jang T, Liu SC, Hurd R, et al. Reversed metabolic reprogramming as a measure of cancer treatment efficacy in rat C6 glioma model. PLoS ONE. 2019;14: e0225313. https://doi.org/10.1371/journal.pone.0225313.

32. Guglielmetti C, Chou A, Krukowski K, Najac C, Feng X, Riparip LK, et al. In vivo metabolic imaging of traumatic brain injury. Sci Rep. 2017;7:17525. https://doi.org/10.1038/ s41598-017-17758-4.

33. DeVience SJ, Lu X, Proctor J, Rangghran P, Melhem ER, Gullapalli R, et al. Metabolic imaging of energy metabolism in traumatic brain injury using hyperpolarized [1-(13)C]pyruvate. Sci Rep. 2017;7:1907. https://doi.org/10.1038/s41598-017-01736-x.

34. Guglielmetti C, Najac C, Didonna A, Van der Linden A, Ronen SM, Chaumeil MM. Hyperpolarized (13)C MR metabolic imaging can detect neuroinflammation in vivo in a multiple sclerosis murine model. Proc Natl Acad Sci USA. 2017;114:E6982-91. https://doi.org/10.1073/pnas.1613345114.

35. Bottomley PA. Human in vivo NMR spectroscopy in diagnostic medicine: clinical tool or research probe? Radiology. 1989;170:1-15.

36. Julià-Sapé M, Candiota AP, Arús C. Cancer metabolism in a snapshot: MRS(I). NMR Biomed. 2019. https://doi.org/10.1002/nbm. 4054.

37. Keshari KR, Wilson DM. Chemistry and biochemistry of $13 \mathrm{C}$ hyperpolarized magnetic resonance using dynamic nuclear polarization. Chem Soc Rev. 2014;43:1627-59. https://doi.org/10.1039/ c3cs60124b.

38. Paasonen J, Stenroos P, Salo RA, Kiviniemi V, Gröhn O. Functional connectivity under six anesthesia protocols and the awake condition in rat brain. Neuroimage. 2018;172:9-20. https://doi. org/10.1016/j.neuroimage.2018.01.014.

39. Hyppönen V, Stenroos P, Nivajärvi R, Ardenkjær-Larsen J-H, Gröhn O, Paasonen J, et al. Metabolism of hyperpolarized [1-13C]pyruvate in awake, isoflurane and urethane anesthetized rat brain. In Proceedings of the 27th Annual Meeting of ISMRM, Paris, France, 2018 Abstract 772.

40. Miller JJ, Grist JT, Serres S, Larkin JR, Lau AZ, Ray K, et al. 13C pyruvate transport across the blood-brain barrier in preclinical hyperpolarised MRI. Sci Rep. 2018;8:15082. https://doi.org/10. 1038/s41598-018-33363-5.

41. Nelson SJ, Kurhanewicz J, Vigneron DB, Larson PE, Harzstark AL, Ferrone M, et al. Metabolic imaging of patients with prostate cancer using hyperpolarized [1-(1)(3)C]pyruvate. Sci Transl Med. 2013;5:198ra08. https://doi.org/10.1126/scitranslmed.3006070.

42. Miloushev VZ, Granlund KL, Boltyanskiy R, Lyashchenko SK, DeAngelis LM, Mellinghoff IK, et al. Metabolic imaging of the human brain with hyperpolarized (13)C pyruvate 
demonstrates (13)C lactate production in brain tumor patients. Cancer Res. 2018;78:3755-60. https://doi.org/10.1158/00085472.CAN-18-0221.

43. Park I, Larson PEZ, Gordon JW, Carvajal L, Chen HY, Bok R, et al. Development of methods and feasibility of using hyperpolarized carbon-13 imaging data for evaluating brain metabolism in patient studies. Magn Reson Med. 2018;80:864-73. https://doi. org/10.1002/mrm.27077.

44. Kurhanewicz J, Vigneron DB, Ardenkjaer-Larsen JH, Bankson JA, Brindle K, Cunningham CH, et al. Hyperpolarized (13)C MRI: path to clinical translation in oncology. Neoplasia. 2019;21:1-16. https://doi.org/10.1016/j.neo.2018.09.006.

45. Crane JC, Gordon JW, Chen HY, Autry AW, Li Y, Olson MP, et al. Hyperpolarized (13) C MRI data acquisition and analysis in prostate and brain at University of California, San Francisco. NMR Biomed. 2020:e4280. https://doi.org/10.1002/nbm.4280.

46. Autry AW, Gordon JW, Chen HY, LaFontaine M, Bok R, Van Criekinge M, et al. Characterization of serial hyperpolarized (13) $\mathrm{C}$ metabolic imaging in patients with glioma. Neuroimage Clin. 2020;27: 102323. https://doi.org/10.1016/j.nicl.2020.102323.

47. Autry AW, Gordon JW, Carvajal L, Mareyam A, Chen HY, Park I, et al. Comparison between 8- and 32-channel phased-array receive coils for in vivo hyperpolarized (13) $\mathrm{C}$ imaging of the human brain. Magn Reson Med. 2019;82:833-41. https://doi.org/ 10.1002/mrm.27743.

48. Sanchez-Heredia JD, Olin RB, McLean MA, Laustsen C, Hansen AE, Hanson LG, et al. Multi-site benchmarking of clinical (13) C RF coils at 3T. J Magn Resonance. 2020;318: 106798. https:// doi.org/10.1016/j.jmr.2020.106798.

49. Larson PE, Bok R, Kerr AB, Lustig M, Hu S, Chen AP, et al. Investigation of tumor hyperpolarized [1-13C]-pyruvate dynamics using time-resolved multiband RF excitation echo-planar MRSI. Magn Reson Med. 2010;63:582-91. https://doi.org/10.1002/mrm. 22264.

50. Gordon JW, Vigneron DB, Larson PE. Development of a symmetric echo planar imaging framework for clinical translation of rapid dynamic hyperpolarized (13) C imaging. Magn Reson Med. 2017;77:826-32. https://doi.org/10.1002/mrm.26123.

51. Gordon JW, Chen HY, Autry A, Park I, Van Criekinge M, Mammoli D, et al. Translation of carbon-13 EPI for hyperpolarized MR molecular imaging of prostate and brain cancer patients. Magn Reson Med. 2019;81:2702-9. https://doi.org/10.1002/mrm.27549.

52. Gordon JW, Autry AW, Tang S, Graham JY, Bok RA, Zhu X, et al. A variable resolution approach for improved acquisition of hyperpolarized (13) C metabolic MRI. Magn Reson Med. 2020;84:2943-52. https://doi.org/10.1002/mrm.28421.

53. Geraghty BJ, Lau JYC, Chen AP, Cunningham CH. Dual-echo EPI sequence for integrated distortion correction in 3D time-resolved hyperpolarized (13) C MRI. Magn Reson Med. 2018;79:643-53. https://doi.org/10.1002/mrm.26698.

54. Reeder SB, Pineda AR, Wen Z, Shimakawa A, Yu H, Brittain JH, et al. Iterative decomposition of water and fat with echo asymmetry and least-squares estimation (IDEAL): application with fast spin-echo imaging. Magn Reson Med. 2005;54:636-44. https:// doi.org/10.1002/mrm.20624.

55. Grist JT, McLean MA, Riemer F, Schulte RF, Deen SS, Zaccagna $\mathrm{F}$, et al. Quantifying normal human brain metabolism using hyperpolarized [1-(13)C]pyruvate and magnetic resonance imaging. Neuroimage. 2019;189:171-9. https://doi.org/10.1016/j.neuro image.2019.01.027.

56. Gordon JW, Chen HY, Dwork N, Tang S, Larson PEZ. Fast imaging for hyperpolarized MR metabolic imaging. J Magn Resonance Imaging. 2021;53:686-702. https://doi.org/10.1002/jmri.27070.

57. Geraghty BJ, Lee CY, Chen AP, Perks WJ, Soliman H, Cunningham $\mathrm{CH}$. Partial Fourier reconstruction for improved resolution in
3D hyperpolarized (13) C EPI. Magn Reson Med. 2020;83:2150 9. https://doi.org/10.1002/mrm.28079.

58. Zhu Z, Zhu X, Ohliger MA, Tang S, Cao P, Carvajal L, et al. Coil combination methods for multi-channel hyperpolarized (13)C imaging data from human studies. J Magn Resonance. 2019;301:73-9. https://doi.org/10.1016/j.jmr.2019.01.015.

59. Larson PEZ, Chen HY, Gordon JW, Korn N, Maidens J, Arcak $\mathrm{M}$, et al. Investigation of analysis methods for hyperpolarized 13C-pyruvate metabolic MRI in prostate cancer patients. NMR Biomed. 2018;31: e3997. https://doi.org/10.1002/nbm.3997.

60. Lee CY, Soliman H, Geraghty BJ, Chen AP, Connelly KA, Endre $\mathrm{R}$, et al. Lactate topography of the human brain using hyperpolarized (13)C-MRI. Neuroimage. 2020;204: 116202. https://doi.org/ 10.1016/j.neuroimage.2019.116202.

61. Uthayakumar B, Lee CY, Bragagnolo ND, Soliman H, Chen AP, Endre R, et al. Hyperpolarized 13C MRI reveals age-related changes in lactate metabolism in the human brain. In Proceedings of the 30th Annual Meeting of ISMRM; 2021.

62. Chung BT, Chen HY, Gordon J, Mammoli D, Sriram R, Autry AW, et al. First hyperpolarized [2-(13)C]pyruvate MR studies of human brain metabolism. J Magn Resonance. 2019;309: 106617. https://doi.org/10.1016/j.jmr.2019.106617.

63. Lee CY, Soliman H, Bragagnolo ND, Sahgal A, Geraghty BJ, Chen AP, et al. Predicting response to radiotherapy of intracranial metastases with hyperpolarized [Formula: see text]C MRI. J Neurooncol. 2021;152:551-7. https://doi.org/10.1007/ s11060-021-03725-7.

64. Hackett EP, Pinho MC, Harrison CE, Reed GD, Liticker J, Raza $\mathrm{J}$, et al. Imaging acute metabolic changes in patients with mild traumatic brain injury using hyperpolarized [1-(13)C]pyruvate. iScience. 2020;23:101885. https://doi.org/10.1016/j.isci.2020. 101885.

65. Autry AW, Park I, Kline C, Chen HY, Gordon JW, Raber S, et al. Pilot study of hyperpolarized (13)C metabolic imaging in pediatric patients with diffuse intrinsic pontine glioma and other CNS cancers. AJNR Am J Neuroradiol. 2021;42:178-84. https://doi.org/10.3174/ajnr.A6937.

66. Goyal MS, Vlassenko AG, Blazey TM, Su Y, Couture LE, Durbin TJ, et al. Loss of brain aerobic glycolysis in normal human aging. Cell Metab. 2017;26(353-60): e3. https://doi.org/10. 1016/j.cmet.2017.07.010.

67. Warburg O. On the origin of cancer cells. Science. 1956;123:309-14. https://doi.org/10.1126/science.123.3191. 309.

68. Lindskog S. Structure and mechanism of carbonic anhydrase. Pharmacol Therap. 1997;74:1-20. https://doi.org/10.1016/s01637258(96)00198-2.

69. Gallagher FA, Sladen H, Kettunen MI, Serrao EM, Rodrigues TB, Wright $\mathrm{A}$, et al. Carbonic anhydrase activity monitored in vivo by hyperpolarized 13C-magnetic resonance spectroscopy demonstrate its importance for $\mathrm{pH}$ regulation in tumors. Cancer Res. 2015. https://doi.org/10.1158/0008-5472.can-15-0857.

70. Autry A, Chung B, Chen H-Y, Gordon J, Lafontaine M, Chang S, et al. Initial experience with hyperpolarized [2-13C]pyruvate MR imaging in patients with IDH-mutant glioma. Neuro-oncology. 2019;21:vi41.

71. Kim Y, Chung BT, Gordon JW, Autry AW, Tan CT, Suszczynski $\mathrm{C}$, et al. Hyperpolarized [2- C]pyruvate molecular imaging with whole brain coverage. In Proceedings of the 30th Annual Meeting of ISMRM; 2021.

72. Josan S, Hurd R, Park JM, Yen YF, Watkins R, Pfefferbaum A, et al. Dynamic metabolic imaging of hyperpolarized [2-(13) C] pyruvate using spiral chemical shift imaging with alternating spectral band excitation. Magn Reson Med. 2014;71:2051-8. https://doi.org/10.1002/mrm.24871. 
73. Park JM, Josan S, Jang T, Merchant M, Watkins R, Hurd RE, et al. Volumetric spiral chemical shift imaging of hyperpolarized [2-(13) c]pyruvate in a rat c6 glioma model. Magn Reson Med. 2016;75:973-84.

74. Subramani E, Najac C, Batsios G, Viswanath P, Radoul M, Gillespie AM, et al. 1H and hyperpolarized 13C MRS biomarkers of IDH1 mutant glioma response to temozolomide therapy. Neuro-oncology. 2018;20:vi101.

75. Dutta P, Salzillo TC, Pudakalakatti S, Gammon ST, Kaipparettu BA, McAllister F, et al. Assessing therapeutic efficacy in real-time by hyperpolarized magnetic resonance metabolic imaging. Cells. 2019;8. https://doi.org/10.3390/cells8040340.

76. Grist JT, Miller JJ, Zaccagna F, McLean MA, Riemer F, Matys T, et al. Hyperpolarized (13)C MRI: a novel approach for probing cerebral metabolism in health and neurological disease. J Cerebral Blood Flow Metabol. 2020;40:1137-47. https://doi.org/10.1177/ $0271678 X 20909045$.

77. Le Page LM, Guglielmetti C, Taglang C, Chaumeil MM. Imaging brain metabolism using hyperpolarized (13)C magnetic resonance spectroscopy. Trends Neurosci. 2020;43:343-54. https://doi.org/ 10.1016/j.tins.2020.03.006.

78. Graham JY, Autry AW, Kim Y, Bok RA, Li Y, Larson PE, et al. Kinetic analysis of multi-resolution hyperpolarized $\mathrm{C}$ human brain MRI. In Proceedings of the 30th Annual Meeting of ISMRM; 2021.
79. Chen HY, Autry AW, Brender JR, Kishimoto S, Krishna MC, Vareth M, et al. Tensor image enhancement and optimal multichannel receiver combination analyses for human hyperpolarized (13) C MRSI. Magn Reson Med. 2020;84:3351-65. https://doi.org/10. 1002/mrm.28328.

80. Kim Y, Chen H-Y, Autry AW, Villanueva-Meyer J, Chang SM, Li Y, et al. Denoising of hyperpolarized 13C MR images of the human brain using patch-based higher-order singular value decomposition. Mag Res Med. 2021. https://doi.org/10.1002/ mrm.28887.

81. Rao Y, Gammon S, Zacharias NM, Liu T, Salzillo T, Xi Y, et al. Hyperpolarized [1-(13)C]pyruvate-to-[1-(13)C]lactate conversion is rate-limited by monocarboxylate transporter- 1 in the plasma membrane. Proc Natl Acad Sci USA. 2020;117:22378-89. https:// doi.org/10.1073/pnas.2003537117.

82. Kubelt C, Peters S, Ahmeti H, Huhndorf M, Huber L, Cohrs G, et al. Intratumoral distribution of lactate and the monocarboxylate transporters 1 and 4 in human glioblastoma multiforme and their relationships to tumor progression-associated markers. Int J Mol Sci. 2020;21. https://doi.org/10.3390/ijms21176254.

83. Viswanath P, Najac C, Izquierdo-Garcia JL, Pankov A, Hong C, Eriksson P, et al. Mutant IDH1 expression is associated with down-regulation of monocarboxylate transporters. Oncotarget. 2016;7:34942-55. https://doi.org/10.18632/oncotarget.9006. 